Síntese - Rev. de Filosofia

V. 28 N. 90 (2001): 37-66

\title{
A CONTEMPORANEIDADE DE ARISTÓTELES NA FILOSOFIA MORAL DE ALASDAIR MACINTYRE
}

Helder Buenos Aires de Carvalho UFPI

Resumo: 0 objetivo do artigo é mostrar que a defesa que Alasdair Maclntyre faz da retomada da ética aristotélica das virtudes, como um remédio filosófico para os males da teoria e da prática morais contemporânea, é uma re-apropriação de ferramentas conceituais da antiguidade clássica, mas moldada por exigências teóricas contemporâneas, especialmente pela inspiração historicista da filosofia da ciência de Thomas Kuhn.

Palavras-chave: Maclntyre, Aristóteles, Ética das Virtudes, Thomas Kuhn.

Abstract: The aim of paper is to show that Alasdair Maclntyre's defense of Aristotelian Ethics of Virtues as a Philosophical solution to the diseases of Contemporary Moral theory and practice is indeed a re-appropriation of Conceptual tools from Classic Antiquity, but influenced by Contemporary Theoretical requirements, especially from Thomas Kuhn's historicist Philosophy of Science.

Key-words: Maclntyre, Aristotle, Virtues Ethics, Thomas Kuhn. 


\section{Introdução}

A

ristóteles é seguramente um dos pensadores gregos antigos que mais tem influído na história filosófica ocidental. Sua presença na reflexão filosófica contemporânea, a despeito da distância em que se situa cultural, histórica e socialmente de nossa época, é facilmente medida pela produção bibliográfica em torno de seu pensamento, funcionando como fermento intelectual poderoso para a reflexão filosófica em nosso século ${ }^{1}$. No campo do pensamento prático, essa força de Aristóteles se fez renovada na Europa continental com a "interpretação existencialista das concepções fundamentais da ética aristotélica indicadas por Heidegger em Sein und Zeit" (BUBNER, 1994, 291) ${ }^{2} \mathrm{Na}$ Alemanha, especialmente, se organizou um movimento que buscou a reabilitação da filosofia prática do Estagirita, nomeado de "neoaristotelismo", em reação à "ciência política" weberiana moderna e à filosofia analítica anglo-saxã . No Canadá e EUA essa mesma tendência se apresenta, dentre outros autores, nas figuras centrais de Charles Taylor e Alasdair MacIntyre 4 .

Este último, objeto de nossa análise, faz uma notável defesa da retomada da ética aristotélica das virtudes como saída para os problemas que diagnostica na linguagem e prática morais de nosso século, associada à recolocação da tradição como locus da pesquisa racional, mas estruturada levando em conta conquistas e exigências filosóficas atuais ${ }^{5}$. Nosso objetivo aqui é mostrar como Maclntyre, ao defender essa retomada da ética aristotélica, identificando a origem de nossos problemas morais nas opções anti-aristotélicas da modernidade, faz uso desse quadro conceptual originário da filosofia grega clássica, mas reformulando-o a partir de categorias oriundas da reflexão históricofilosófica sobre a atividade científica feita por Thomas Kuhn, influente filósofo da ciência de nossa época.

Em nossa abordagem utilizaremos metáforas médicas para explicitar a organização dos três momentos fundamentais do enfrentamento macintyreano do problema da racionalidade ética e sua relação com a

\footnotetext{
1 Para uma visão geral dessa presença de Aristóteles na cultura filosófica do século 20, ver BERTI (1998). Ver também GUARIGLIA (1990) para uma visão no âmbito da filosofia da ação e da filosofia moral.

2 Segundo Bubner, "ainda que a evolução da filosofia inglesa não tenha seguido o caminho do resto da Europa, o aristotelismo, tido por tradicional em Oxford, cumpriu sem dúvida um papel comparável ao do continente desde o pós-guerra" (BUBNER, 1994, 291).

${ }^{3}$ Ver o artigo de BERTI (1990) para uma visão geral de sua evolução na Alemanha.

${ }^{4}$ Ver WALLACH (1992) para o que se chamaria um "Aristotelian Turn" na filosofia política contemporânea, especialmente anglo-saxã.

${ }^{5}$ Ver o meu livro CARVALHO (1999) para una introdução à sua filosofia moral.
} 
tradição, no qual está contextualizada sua apropriação da ética aristotélica: primeiro, o diagnóstico que ele faz da condição da linguagem moral e da moralidade contemporânea; segundo, a medicação que ele oferece para solucionar as dificuldades teóricas e práticas identificadas no diagnóstico; e, por fim, a posologia, ou seja, a dose e a extensão com que essa medicação deve ser utilizada para solucionar tais dificuldades e problemas. Essa estratégia se justifica pela própria posição que Maclntyre adota nos seus escritos em relação às dificuldades da teoria e da prática morais contemporâneas, similar à de um médico que, após identificar as verdadeiras causas dos males que afligem a nossa cultura, empreende a tarefa de engendrar um remédio eficaz para sua cura.

\section{O diagnóstico: o desacordo crônico da moralidade contemporânea}

Maclntyre parte da tese de que a linguagem da moralidade contemporânea está num estado tão grave de desordem que não possuímos mais que "fragmentos de um esquema conceptual" (AV, 2), os quais já não dispõem dos contextos sociais e culturais anteriores em cujo interior adquiriam sentido e função. A moralidade contemporânea é, na verdade, um simulacro de moralidade, uma coleção de fragmentos de moralidades passadas que não formam mais um todo coerente; perdemos toda a possibilidade conceptual de formular critérios morais de modo integrado e objetivo, isto é, uma concepção unificadora e ordenadora do espaço da moralidade que a tornava inteligível.

Segundo ele, são três as características principais desse desacordo moral na nossa cultura:

1) A incomensurabilidade conceptual dos argumentos rivais, isto é, cada um dos argumentos das teorias rivais envolvidas é logicamente válido, mas as premissas rivais empregam conceitos valorativos ou normativos inteiramente diferentes uns dos outros, de tal forma que as pretensões levantadas com base neles são de tipos completamente diferentes, a ponto de "quando chegamos às nossas premissas, a discussão cessa e a invocação de uma premissa contra a outra torna-se uma questão de pura asserção e contra-asserção" (AV, 8). 0 resultado é um cinismo generalizado quanto à legitimidade da discussão racional, no qual as questões morais são tratadas no domínio público como situadas fora da pesquisa racional.

2) Contrastando com a primeira característica, essas discussões pretendem ser discussões racionais impessoais, dando um ar paradoxal ao desacordo moral contemporâneo, visto que, de um lado, podemos concluir que nele não há nada mais que um choque de vontades antagonistas, 
cada vontade sendo determinada por suas próprias escolhas arbitrárias; de outro lado, temos a exigência de a linguagem moral ser um apelo a padrões objetivos, racionais, indicando que a prática da discussão moral em nossa cultura pelo menos aspira a ser ou a tornar-se racional. Entretanto, o recurso a padrões de racionalidade produz um novo nível de diferenças e conflitos, pois quando a discordância entre as teorias morais é tão fundamental, essa discordância vai se estender também ao modo como se deveria proceder para resolvê-las, ao modo mesmo do que se considera ser.

3) A terceira característica, e intimamente vinculada às outras duas, é relativa ao fato das premissas incomensuráveis envolvidas nos argumentos rivais possuírem uma heterogeneidade de origens históricas. Como esses diversos conceitos que informam nosso discurso moral estavam originalmente integrados em totalidades maiores de teoria e prática, eles agora estão desprovidos dos contextos nos quais ocupavam um papel e função. 0 resultado é que somos levados pela educação a adotar um modo incoerente e desordenado de pensar e julgar, isto é, uma visão que foi elaborada com base em um amálgama de fragmentos sociais e culturais herdados de diferentes tradições, gerando um pluralismo moral de natureza superficial, fragmentado, que não é um diálogo ordenado entre pontos de vista que se interseccionam, e sim uma mistura de fragmentos mal combinados.

Mas o que conduziu a linguagem moral contemporânea a esse estado fragmentado, no qual seu discurso é tensamente caracterizado, de um lado, pela multifariedade e aparente incomensurabilidade dos conceitos invocados, e, de outro, pelo uso assertivo de princípios últimos nas tentativas de encerrar o debate moral? Segundo Maclntyre, é preciso ter em conta que somos os últimos herdeiros, o produto final de um processo de mudança histórica no qual o discurso moral, a linguagem da moralidade, também foi transformado ao mesmo tempo. Nossa cultura geral e nossa filosofia acadêmica são filhas de uma cultura - a cultura iluminista, forjada no nordeste da Europa no século XVIII - que não conseguiu resolver seus problemas práticos e filosóficos, cujo fracassado projeto de justificar a moralidade determinou a forma dos nossos atuais problemas filosóficos e sociais.

Esse projeto iluminista é descrito como centralmente preocupado em dar à moral uma justificação racional, independente da tutela teológica e das tradições, no intuito de dar-Ihe total autonomia na forma de princípios morais universais. A despeito do fato de que os pensadores iluministas discordassem sobre os princípios que constituiriam tal moralidade universal, eles propagaram a crença de que tais princípios existiam e que a conduta moral teria de estar sujeita à validação ou crítica inteligível. Entretanto, a própria inexistência de uma grade de valores hegemônicos, a partir da qual os juízos morais pudessem estar de acordo, revelou que este ideal não poderia ser atingido. Para 
Maclntyre, os pensadores iluministas fracassaram e deviam fracassar nesse intento de fundar uma moralidade universal porque compartilhavam um fundo histórico comum de crenças morais, herdado do seu passado cristão, mas privado do esquema teleológico que lhe dava coerência e sustentação: o esquema teleológico da Ética a Nicômaco de Aristóteles.

Um fracasso causado por algumas características partilhadas por todos, derivadas de seu contexto histórico específico: a primeira dessas características, herdada do passado cristão partilhado, é que todos concordam no fundamental quanto ao conteúdo e o caráter dos preceitos que constituem a genuína moralidade; ao mesmo tempo, segunda característica, também concordam quanto à definição do que é uma justificação racional da moralidade: as premissas fundamentais explicitariam algum traço ou traços da natureza humana, a justificação, então, seria a construção de argumentos válidos que se moveriam dessas premissas até conclusões sobre a autoridade das regras e preceitos morais. Mas esse projeto estava fadado ao fracasso por causa de "uma discrepância ineliminável entre, de um lado, sua concepção comum de regras e preceitos morais e, de outro lado, o que era comum - a despeito de grandes divergências - às suas concepções da natureza humana" (AV, 52).

A estrutura básica do esquema moral clássico está no esquema teleológico de Aristóteles, explicitado na Ética a Nicômaco, no qual há um contraste fundamental entre uma natureza-humana-tal-como-existe (concepção da natureza humana no seu estado não-instruído, como o homem é) e uma natureza-humana-tal-como-seria-se-realizasse-o-seutelos (concepção do homem como ele seria se realizasse sua natureza essencial). E a ética é precisamente a ciência que capacitaria os homens a transitar do estado não-instruído para aquele em que realiza plenamente sua essência de ser racional, o seu telos. Os preceitos morais nos dão justamente o caminho certo para sairmos da potencialidade ao ato, para entendermos nossa verdadeira natureza e para alcançarmos nosso verdadeiro fim. Há, dessa forma, uma estrutura tríplice nesse esquema moral clássico, cujos termos estão articulados de tal maneira que não poderemos entender o status e as funções de cada um sem referência aos outros.

Entretanto, essa parcela fundamental do esquema clássico não sobrevive com a modernidade, porque esta incorpora uma nova concepção de razão: degradada em seus poderes e concebida como não podendo mais suprir uma genuína compreensão do verdadeiro fim do homem, não tem mais o poder de corrigir nossas paixões. É justamente a rejeição secular tanto da teologia católica como da protestante - que ainda retinham o elemento teleológico do esquema clássico - somada à rejeição científica e filosófica do aristotelismo que pulverizou toda possibilidade de qualquer noção do homem-como-seria-se-realizasse-o-seutelos. Essa eliminação de qualquer concepção da natureza essencial do 
homem e do seu telos faz com que se produza um esquema moral composto de dois elementos, remanescentes do esquema clássico, cujas relações internas se tornam agora inteiramente confusas. Sem a noção de um telos para que os preceitos morais cumpram sua função mediadora de passagem do estado original para a realização da essência do homem, as injunções morais se transformam em preceitos que vão de encontro às tendências da natureza humana concebida nãotel eol ogicamente.

0 fracasso do projeto iluminista demarcou toda a problemática da teoria moral moderna, fazendo-a girar em torno da necessidade de devolver a validade racional às regras morais. Quando, de um lado, liberou o agente moral de todo e qualquer vínculo com hierarquias e teleologias, tornando-o autônomo e soberano na determinação dos conteúdos morais; e, de outro lado, transformou as regras morais de tal forma que elas perderam o estatuto factual e categórico que possuíam e se tornaram meros instrumentos dos desejos e vontades arbitrários de um agente moral individual, o lluminismo tornou agudo o problema de se encontrar uma nova teleologia ou um novo estatuto categórico para as regras da moralidade, de tal forma que o recurso a elas se tornasse novamente racional, mas ao mesmo tempo mantendo a autonomia do agente moral individual.

O utilitarismo é o melhor exemplo das tentativas do primeiro tipo, isto é, buscar uma nova teleologia para a moralidade e, com isso, fornecer um novo status às regras morais e um novo significado aos conceitos morais centrais, em bases psicológicas. Entretanto, essa derivação da moralidade a partir da psicologia encontra sérias dificuldades, em função do reconhecimento do caráter polimorfo do prazer e da felicidade, tornando tais conceitos sem uso para os propósitos utilitaristas. E mesmo a filosofia analítica, representativa das tentativas do segundo tipo, para Maclntyre, também não conseguiu responder satisfatoriamente aos desafios postos para a teoria moral moderna a partir do fracasso do projeto iluminista, nesse caso, de combinar consistentemente a autonomia do agente moral individual com uma visão das regras morais como tendo uma autoridade objetiva e independente.

0 que esse fracasso do utilitarismo da metade e do final do século XIX e da filosofia moral analítica da metade e do final do século XX nos revela com maior agudeza, segundo Maclntyre, é justamente a incoerência presente no esquema moral do século XX. Mas a principal conseqüência do fracasso do projeto iluminista de justificação racional da moralidade que ele aponta para a cultura das sociedades contemporâneas é a encruzilhada final a que conduziu: a escolha entre sustentar o projeto nietzscheano de uma crítica radical da moralidade ou retomar a perspectiva da ética aristotélica das virtudes como forma de devolver coerência e racionalidade ao desacordo moral que reina na cultura moderna. 
Maclntyre encara a análise nietzscheana da moralidade como o ápice do individualismo liberal, o resultado maior do projeto iluminista de um sujeito moral autônomo concebido à parte e anteriormente à sociabilidade histórica, pois Nietzsche teve o mérito e a coragem de radicalizar conscientemente o fracasso do projeto iluminista de uma moralidade universal racional. Melhor que qualquer outro pensador, foi Nietzsche quem percebeu que a linguagem moral na modernidade estava disponível para qualquer uso, que a moral podia agora ser performada para um número considerável de causas, que a forma dos proferimentos morais modernos fornecia uma máscara possível para qualquer rosto. Ele entendeu claramente que aquilo que na linguagem moral do lluminismo parecia ser apelo à objetividade era, de fato, expressão da vontade subjetiva; e percebeu também a natureza dos problemas que isto colocava para a filosofia moral. 0 erro dele foi generalizar ilegitimamente da condição do juízo moral em sua própria época para a natureza da moralidade enquanto tal. Segundo Maclntyre, a grandeza de Nietzsche reside exatamente na sua implacável perseguição do problema, não nas frívolas soluções que oferece, e "que faz dele o filósofo moral se as únicas alternativas à filosofia moral de Nietzsche mostrarem-se ser aquelas formuladas pelos filósofos do lluminismo e seus sucessores" (AV, 114).

\section{O medicamento: retorno à ética aristotélica das virtudes}

Diante da encruzilhada entre seguir Nietzsche ou retomar Aristóteles, Maclntyre faz a segunda opção como o remédio para os males da herança iluminista da modernidade, mas na perspectiva de uma tradição de pesquisa racional, isto é, encarar a filosofia moral de Aristóteles como o núcleo central de toda uma tradição de pesquisa e de prática social, da qual ele não é o único representante, ainda que seja o que lhe forneceu os principais parâmetros de sua formulação e desenvolvimento. Para ele, se quisermos sair do imbróglio em que estamos, precisamos recuperar justamente aquilo do qual o lluminismo nos privou, isto é, uma concepção da pesquisa racional que seja inseparável da tradição social e intelectual em que está incorporada, "concepção de acordo com a qual os próprios padrões de justificação avultem e façam parte de uma história na qual eles sejam exigidos pelo modo como transcendem as limitações e fornecem soluções para as insuficiências de seus predecessores, dentro da história dessa mesma tradição" (JR, 18). Quer dizer, uma concepção da racionalidade estruturada como uma narrativa histórica, em que 0 conceito de justificação é essencialmente histórico.

Maclntyre opera aqui com uma conceituação da tradição, não como algo que é repassado estaticamente através das gerações e se manifesta 
imutavelmente na vida social e cultural das comunidades que vivem sob seu signo, mas sim como portadora de uma dinâmica interna, na qual o conflito tem um lugar necessário na sua constituição. A tradição é, assim, definida como uma argumentação

\begin{abstract}
"desenvolvida ao longo do tempo, na qual certos acordos fundamentais são definidos e redefinidos em termos de dois tipos de conflitos: os conflitos com críticos e inimigos externos à tradição que rejeitam todos ou pelo menos partes essenciais dos acordos fundamentais, e os debates internos, interpretativos, através dos quais o significado e a razão dos acordos fundamentais são expressos e por cujo progresso uma tradição é constituída" (JR, 23).
\end{abstract}

Os conflitos internos ocasionalmente podem destruir o acordo fundamental comum, gerando uma divisão na tradição entre dois ou mais componentes em conflito, transformando seus adeptos em críticos externos mútuos, ou mesmo levar a tradição à incoerência e à dissolução. Pode também acontecer que duas tradições, até então independentes e mesmo antagônicas, passem a reconhecer certas possibilidades de acordo fundamental e se reconstituam como um debate único e mais complexo. Nesse sentido, a narrativa histórica de uma tradição implica "uma narrativa da pesquisa e do debate dentro de uma tradição e também uma narrativa do debate e da discordância en tre uma tradição e suas adversárias, debates e discordâncias que definem pormenorizadamente os diversos tipos de relações antagônicas" (JR, 376). Só podemos identificar adequadamente nossos próprios compromissos e os dos outros se os situarmos dentro das histórias, internas às respectivas tradições, que os fizeram ser o que são hoje.

Segundo Maclntyre, precisamos nos desvencilhar dos usos ideológicos que 0 conceito de tradição tem sofrido por parte dos teóricos políticos conservadores, que têm seguidamente mantido o contraste que Burke fez entre tradição e razão, entre a estabilidade da tradição e o conflito, pois ambos obscurecem sua conceituação. Ao contrário disso, o raciocínio de um agente moral sempre acontece no interior de algum modo tradicional de pensamento, quer dizer, o espaço da racionalidade é 0 espaço interno da tradição. Quando uma tradição está em bom estado, não significa ser algo estável e perene, imóvel na sua posição e nas suas formulações, ao contrário, ela é sempre constituída parcialmente por uma discussão em torno dos bens cuja busca dá sentido e propósito a essa tradição. A pesquisa racional é sempre uma linha de discussão em torno dos bens internos à tradição social mais ampla da qual ela é constitutiva e pela qual é constituída. Daí porque afirma que as tradições vivas significam uma continuidade de conflitos. Para ele, quando uma tradição se torna o que Burke descreve como tradição, ela está morrendo ou já está morta. Uma tradição viva é, então,

"uma discussão historicamente estendida, socialmente encarnada, e uma discussão precisamente em parte acerca dos bens que constituem essa tradição. 
Dentro de uma tradição a busca dos bens estende-se através das gerações, algumas vezes por muitas gerações. Daí que a busca individual pelo bem da cada um é, de um modo geral e característico, conduzida dentro de um contexto definido por essas tradições das quais a vida dos indivíduos é uma parte, e isto é verdade tanto desses bens que são internos às práticas quanto dos bens de uma vida única" (AV, 222).

Maclntyre julga encontrar na filosofia de Aristóteles o exemplo maior dessa compreensão da pesquisa racional ou filosófica como tradição, isto é, da pesquisa racional constituída pela tradição e constitutiva dela, como resposta sistemática às questões pré-filosóficas da comunidade social de práticas a que se vincula. A ética e a política de Aristóteles, entendidas como tendo uma dimensão metafísica sistemática, foram uma resposta às aporiai atenienses oriundas da variedade de constituições políticas em competição, da variedade de opiniões acerca do que é o bem humano, do que são as virtudes e de como as virtudes particulares devem ser entendidas, dos desacordos em torno do tipo de educação que melhor capacitaria os jovens a atuar bem. Em tal modo de filosofar, o estudante imaturo, jovem inexperiente e indisciplinado, oriundo das elites governantes da polis e para cujos quadros retornaria posteriormente, tinha de se submeter à educação de um conjunto de virtudes morais e intelectuais, cujo sentido e propósito ele só saberia apreciar quando as tivesse adquirido plenamente. Quer dizer,

"no chegar a entender o bem humano, as verdades sobre esse bem, que vão ser obtidas por uma árdua pesquisa, têm que estar já pressupostas nas primeiras fases dessa pesquisa, pelo modo no qual a pesquisa tem de ser organizada em seu início. Este tipo de circularidade envolvida no iniciar e conduzir a pesquisa filosófica, que Aristóteles deixa tão claro para nós, eu considero ser um traço ineliminável da filosofia sistemática. Nosso telos, nosso fim, teórico ou prático, já está em nossos começos" (SH, 74-5).

Isso significa que a filosofia, ao nos ajudar a enfrentar as aporiai, as dificuldades presentes em nossa condição pré-filosófica, tornando-nos conscientes de suas incoerências e ininteligibilidade ao explicitar as assunções filosóficas que estão na base de nossas crenças e discursos pré-filosóficos, exige que enfrentemos essas dificuldades de uma maneira que pressupomos justamente aquilo que ainda temos de aprender. Segundo MacIntyre, é assim que Aristóteles procede no livro $K$ da Metafísica, ao defender o princípio da não-contradição, bem como em outros lugares, ainda que algumas vezes não tão obviamente.

Portanto, a filosofia sistemática começa quando uma variedade tão grande quanto possível de problemas, incoerências e ininteligibilidade parciais do discurso pré-filosófico, da ação e da pesquisa são tornadas objeto de uma pesquisa na qual as questões a serem respondidas têm a seguinte forma: "Como todas essas questões devem ser entendidas à 
luz da mais unificada e integrada concepção de pesquisa racionalmente adequada possuída até aqui?". Nesse sentido, toda concepção bem desenvolvida de adequação racional é uma concepção interna a algum sistema filosófico particular; na verdade, "de certo ponto de vista, um sistema filosófico particular éjustamente uma concepção da adequação racional bem desenvolvida, unificada e integrada" (SH, 76). Pois todo sistema filosófico, desde o início do desenvolvimento de suas explicações racionais desta ou daquela área do discurso, da ação ou da pesquisa, pressuporá tacitamente ou invocará explicitamente uma concepção do telos da pesquisa, que, por sua vez, será sustentado pelo apelo aos resultados derivados daquelas explicações.

$\mathrm{Na}$ concepção de Maclntyre, as tradições de pesquisa racional ou sistemas filosóficos históricos são elaborações de ideais de adequação racional, tanto teóricos como práticos, das crenças, argumentos, asserções e práticas multifárias, cujos traços persistentes forçaram as pessoas esclarecidas a um reconhecimento da necessidade de levantar questões filosóficas sobre aquelas crenças, argumentos, asserções e práticas. Quer dizer, sistemas filosóficos continuam a ter um objeto identificável quando há um conjunto mais ou menos contínuo de intercâmbios dialéticos entre os filósofos engajados em articular algum sistema filosófico particular e aquelas pessoas esclarecidas, pré-filosóficas, que estão engajadas em levantar questões sobre a adequação racional de suas crenças e práticas, questões essas que emergem no discurso e na interação quotidiana deles, bem como das investigações teológicas e científicas, das atividades políticas, jurídicas e estéticas, e assim por diante.

A filosofia moral macintyreana não faz uma reapropriação de Aristóteles tal como está expressa e isolada nos textos-chaves de sua obra, mas inserindo-a numa narrativa histórica mais ampla, situando-a como um momento particular de uma seqüência maior em que assume boa parte da produção teórica que Ihe antecedeu e, ao mesmo tempo, é fonte e estímulo para a reflexão filosófica que lhe sucedeu, isto é, inscrevendo a perspectiva aristotélica numa história das concepções de virtude, na qual Aristóteles fornece 0 eixo central, gerando os recursos de uma tradição inteira de pensamento, ação e discurso, mas da qual ele próprio é apenas uma parte. Entretanto, essa é uma abordagem claramente nãoaristotélica, pois tratar Aristóteles como parte de uma tradição, mesmo como seu maior representante, é assumir uma perspectiva epistemológica que o próprio Aristóteles jamais pretendeu, uma perspectiva na qual a reflexão atual só tem sentido na sua ligação com a história passada, como parte do fio argumentativo histórico que uma tradição tece.

Numa tradição de pesquisa racional é imanente uma amarração historicista entre passado, presente e futuro, pois nela é reconhecido um processo histórico em que o passado é corrigido e transcendido pelo presente, não de uma forma necessária, mas contingencial, deixando também aberta a possibilidade de que essa construção do presente, por 
sua vez, possa ser corrigida e transcendida por uma construção mais adequada no futuro. Em tal perspectiva epistemológica, a última teoria da série não é necessariamente superior às primeiras, pois uma tradição também tem diante de si a possibilidade de estagnar-se, de deixar de progredir ou mesmo degenerar segundo seus próprios padrões. Nesse sentido, a noção de tradição "encarna uma teoria do conhecimento verdadeiramente não-aristotélica, de acordo com a qual cada teoria ou conjunto de crenças científicas ou morais é intel igível e justificável - na medida em que é justificável - somente como membro de uma série histórica" (AV, 146).

O que Maclntyre nomeia de "tradição clássica" é um tipo de tradição cuja existência o próprio Aristóteles não reconheceu e nem poderia reconhecer, pois os pensadores gregos não operavam com qualquer sentido do histórico na nossa acepção contemporânea, impedindo-o de reconhecer seu próprio pensamento como parte de uma tradição. Maclntyre tem claro que o papel central de Aristóteles para a tradição clássica não significa que ele deva ser considerado infalível no trato com as questões que emergiram no interior dessa mesma tradição. Algumas questões centrais para a tradição clássica não podem ser respondidas pelo próprio Aristóteles. M as, a despeito disso, é a interpretação aristotélica das virtudes que constituiu decisivamente a tradição clássica como "uma tradição de pensamento moral" (AV, 147), que tornou a Ética a Nicômaco o texto canônico para a interpretação aristotélica das virtudes.

Mas quais são precisamente os elementos constitutivos dessa tradição clássica, além do núcleo aristotélico, que MacIntyre propõe retomar como uma tradição de pesquisa racional capaz de repor a racionalidade da moralidade? Maclntyre faz um levantamento das concepções de virtude em cada um dos estágios dessa tradição clássica de pensamento e ação no intuito de fazer emergir as raízes dos elementos fundamentais que a compõem: das sociedades heróicas advém o vínculo visceral entre virtude e estrutura social; de Atenas e seus poetas e teatrólogos, a visão do conflito como central à vida humana, a compreensão da vida humana e de sua unidade como portadora de uma estrutura narrativa dramática; de Aristóteles advém o esquema teleológico das virtudes, o vínculo com a pólis, o nexo entre inteligência prática e virtude, o caráter do raciocínio prático e a superioridade da virtude sobre as regras; e, por fim, do período medieval, a componente propriamente histórica que é acrescentada a esse esquema narrativo da compreensão da vida humana como um todo.

Maclntyre defende que é possível extrair, da variedade de concepções rivais que a história da moralidade nos apresenta, um conceito nuclear unitário das virtudes que ofereça uma explicação mais convincente do que qualquer outra dada até agora, um conceito que consiga dar à tradição aristotélica ou clássica de pesquisa racional sua unidade conceptual. Mas é um conceito complexo porque tem suas diferentes partes constituídas em diferentes estágios do desenvolvimento da tradição, quer dizer, "o próprio conceito, num certo sentido, encarna a história 
da qual ele é o resultado" (AV, 186). Ele tem pelo menos três estágios no seu desenvolvimento lógico e cada um deles pressupõe seu próprio panode-fundo conceptual contra o qual vai ser entendido. Cada um desses estágios é modificado e reinterpretado pelo que lhe é posterior, mas ao mesmo tempo é um constituinte essencial dele. Daí porque o progresso no desenvolvimento do conceito estar estreitamente vinculado à história da qual ele é o núcleo, não podendo ser compreendido fora dela.

Vejamos, então, o primeiro estágio desse conceito, cujo sentido e função se define tendo como condição de inteligibilidade o conceito de "prática". Para Maclntyre, é sempre um tipo particular de prática que providencia a arena na qual as virtudes vão ser exibidas e recebem sua definição, ainda que primária e incompleta - uma vez que as virtudes não são exercidas exclusivamente no âmbito das práticas. "Prática" é definida, diferentemente do uso ordinário da palavra, como

"qualquer forma complexa e coer ente de atividade cooperativa humana, socialmente estabelecida, por meio da qual bens internos são realizados na busca de alcançar aqueles padrões de excelência que são apropriados e parcialmente definidores dessa forma de atividade, resultando que os poderes humanos para alcançar a excelência, e as concepções dos fins e bens envolvidos, são sistematicamente ampliados" (AV, 187).

Nesse sentido, dar um chute com habilidade numa bola não é uma prática, mas o jogo de futebol é; plantar batatas não é uma prática, mas a agricultura é; levantar paredes não é uma prática, mas arquitetura é. E assim são práticas as pesquisas da física, química e biologia, o trabalho do historiador, a pintura e a música, etc., uma variedade ampla que abrange desde artes, ciência, jogos, política, até a formação e a sustentação da vida familiar.

Segundo Maclntyre, dois tipos de bens podem ser obtidos quando alguém se engaja numa prática: os bens externos, que são contingentes às práticas por força das circunstâncias sociais - por exemplo, 0 prestígio, o status e o dinheiro para um adulto, os bombons ou brinquedos no caso de uma criança - , isto é, tais bens não estão necessariamente vinculados às práticas, podendo ser obtidos por diversos outros meios que não somente se engajando em algum tipo de prática particular. Do outro lado, os bens internos de uma prática, que podem ser obtidos única e exclusivamente no engajamento em alguma prática particular, envolvendo padrões de excelência entendidos historicamente e encarnando um certo tipo de vida; tais bens são chamados internos porque eles só podem ser especificados nos termos dessa prática e por meio de exemplos dela, e também porque só podem ser identificados e reconhecidos na experiência de participar dessa prática.

Numa prática sempre estão envolvidos padrões de excelência e de obediência a regras, bem como de obtenção de bens, que se colocam 
como tendo uma autoridade acima das subjetividades, visto que "entrar numa prática é aceitar a autoridade desses padrões e a inadequação de minha própria performance julgada por eles" (AV, 190). Não conseguiremos aprender uma prática sem primeiro aceitar a autoridade dos melhores padrões instituídos até aquele momento, que corrente e parcialmente definem a prática. Essa dimensão "conservadora" é essencial para a continuidade da prática e para seu avanço, como também para evitar juízos subjetivistas e emotivistas, quer dizer, nesses padrões de excelência e na percepção e obtenção dos bens inerentes a uma prática há sempre a pretensão à objetividade. Maclntyre observa que as práticas também têm uma história, por isso os padrões de excelência que Ihe são constituintes não estão imunes às críticas, sofrem alterações no seu desenvolvimento histórico. Entretanto, em qualquer prática, se eu quiser aprendê-la, tenho de admitir de início que os outros conhecem melhor do que eu o fazer e o avaliar, segundo seus padrões de excelência, as atividades envolvidas na prática em questão, e a partir daí aprender com os outros como fazer bem e avaliar segundo os padrões de excelência que Ihes são internos e, quem sabe, poder até mesmo avançar e aperfeiçoar tal fazer e tais padrões.

Com isso, podemos compreender outra diferença - essencial para entendermos o papel das virtudes no interior das práticas - entre os bens externos e os bens internos a ela. Os bens externos são caracteristicamente posse ou propriedade de um indivíduo, eles sempre envolvem uma competição na qual existirão perdedores e vencedores, como é o caso do poder, da fama e do dinheiro. Já os bens internos, ao contrário, são o resultado da competição em busca da excelência, mas sua obtenção enriquece toda a comunidade, é um bem para todos aqueles que participam da prática, não envolvem a existência de perdedores e vencedores. MacIntyre, então, define virtude como exatamente "uma qualidade humana adquirida cuja posse e exercício tende a nos capacitar a alcançar aqueles bens que são internos às práticas e cuja falta efetivamente nos impede de alcançá-los" (AV, 191). Sem as virtudes, os bens internos às práticas não vão ser alcançados, pois na medida em que toda prática exige um certo tipo de relações entre aqueles que dela participam, a função das virtudes vai ser determinar a natureza das relações entre os sujeitos no interior dessa prática. Daí porque considera as virtudes da justiça, da coragem e da honestidade como componentes necessários de qualquer prática com bens internos e padrões de excelência, porque são elas que vão garantir nossa relação com os outros praticantes na direção dos bens internos da prática em questão. Isso significa que em sociedades com códigos muito diferentes acerca do que seja honestidade, justiça e coragem, práticas podem se desenvolver, mas não poderão florescer em sociedades nas quais as virtudes foram deixadas de lado, desvalorizadas e não cultivadas.

Entretanto, adverte que o escopo de qualquer virtude na vida humana se estende para além das práticas em cujos termos é inicialmente de- 
finida, pois as virtudes têm um papel em campos mais amplos da vida humana - e aqui passamos para o segundo estágio do conceito de virtude que $M$ aclntyre propõe - , seu sentido e função não se limitando às práticas. Se restringirmos a definição do conceito de virtude ao âmbito das práticas, fatalmente chegaremos a uma situação em que a possibilidade do conflito trágico se efetiva, uma situação em que as pretensões de uma prática podem ser incompatíveis com as de outras, ambas apontando para direções diferentes, de tal forma que podemos nos ver oscilando, de um modo arbitrário, entre uma posição e outra, sem conseguirmos constituir propriamente uma escolha racional.

Para escapar desse elemento arbitrário na vida moral e conseguir dar consistência ao conceito de virtude como central à vida moral, é preciso que incorporemos um segundo passo na sua constituição, isto é, a incorporação de uma concepção do telos de uma vida humana inteira, concebida como uma unidade, na qual haja uma compreensão dos bens e do bem que vai além da multiplicidade de bens que informam uma prática.

"A menos que haja um telos que transcenda os bens limitados das práticas, constituindo o bem de uma vida humana inteira, o bem de uma vida humana concebida como uma unidade, tanto uma certa arbitrariedade subversiva invadirá a vida moral, como também seremos incapazes de especificar adequadamente o contexto de certas virtudes" (AV, 203).

Isso significa dizer que esse conceito de virtude que Maclntyre propõe exige um modelo de racionalidade da ação humana que concebe cada vida humana como tendo uma unidade, de tal forma que cada vida possa ser justificada como tendo seu bem e as virtudes possam ser entendidas como tendo a função de habilitar cada indivíduo a fazer de sua vida um tipo de unidade, e não outro. E pensar a vida humana como um todo, como portadora de uma unidade que fornece um telos para as virtudes, é pensar de uma maneira contrária ao modus vivendi da sociedade moderna, que divide cada vida humana numa variedade de segmentos, cada um com suas próprias normas e modos de comportamentos, separando o trabalho, do lazer, a vida privada, da vida pública, o coletivo, do pessoal.

0 que está em jogo nesse conceito macintyreano de virtude é um conceito do eu pensado de um modo narrativo, isto é, um eu que não se reduz a episódios fragmentados e isolados na ordem temporal, cuja unidade é a unidade de uma narrativa que liga nascimento, vida e morte, ou seja, que tem início, meio e fim. Para Maclntyre, toda ação humana só pode ser compreendida no interior de uma história narrativa que articula intenções, crenças e ambientação social de um agente de um modo histórico. Daí ele afirmar que certo tipo de narrativa histórica seja "o gênero básico e essencial para a caracterização das ações humanas" (AV, 208). O que distingue a ação humana daquela de outros seres é que podemos identificá-la sob um tipo de descrição que nos 
possibilita vê-la fluindo inteligivelmente das intenções, motivos, paixões e propósitos de um agente humano, quer dizer, tendo um responsável por ela, a quem podemos sempre nos dirigir e pedir uma explicação inteligível. Assim, toda ação só se torna inteligível encontrando seu lugar numa narrativa, quando situamos um episódio particular no contexto do conjunto de histórias narrativas, tanto dos indivíduos envolvidos como dos contextos sociais nos quais agem e interagem.

Para Maclntyre, podemos mesmo dizer que toda ação nada mais é do que uma narrativa performada, concretizada. E isso só é possível porque a própria ação tem uma natureza basicamente histórica: “É porque todos nós vivemos narrativas em nossas vidas e porque nós entendemos nossas próprias vidas nos termos das narrativas que vivemos, que a forma da narrativa é apropriada para entendermos a ação dos outros" (AV, 212). M as essas narrativas históricas nas quais cada indivíduo, cada eu, encontra sua unidade não são, a rigor, narrativas isoladas, pois uma narrativa pode estar mergulhada, inserida numa outra. $\mathrm{Na}$ verdade, cada um de nós é personagem de uma variedade de narrativas ao mesmo tempo, muitas delas umas dentro das outras, porque não somos mais que co-autores de nossas próprias narrativas. Quer dizer, uma ação não pode ser compreendida sem uma narrativa que lhe dê sentido, que a situe no interior de um enquadramento histórico, seja de uma única história, seja de várias histórias que se interseccionam. "Uma ação é um momento numa história real ou possível ou num sem número de tais histórias. A noção de uma história é uma noção tão fundamental quanto a noção de uma ação. Cada uma exige a outra" (AV, 214).

A rigor, para Maclntyre, a vida individual consiste na unidade de uma narrativa encarnada numa vida singular, que na forma de atos e palavras tenta responder sistematicamente às questões acerca do que é bom para cada indivíduo e do que é bom para o homem. É o tecido histórico dos significados formado pelas respostas a essas duas questões que constitui a unidade da vida moral tanto para um indivíduo como para a comunidade. Isso significa estabelecer a unidade de uma vida humana como a unidade de um relato de busca ${ }^{6}$, mas uma busca que é orientada por um telos, mais precisamente, por alguma concepção do bem para o homem que nos permita ordenar outros bens, ampliar nossa compreensão do propósito e conteúdo das virtudes, entender 0 lugar da integridade e da constância na vida, definindo com isso, ao final, o tipo de vida que é uma busca pelo bem. Mas uma busca pelo bem não como algo já definido e pronto, e sim envolvendo um aprendizado con-

\footnotetext{
6 "Buscas algumas vezes fracassam, são frustradas, abandonadas ou dissipadas em distrações, e as vidas humanas podem, de todos esses modos, também fracassarem. Mas o único critério para sucesso ou fracasso numa vida humana tomada como um todo são os critérios de sucesso ou fracasso numa busca narrada ou a ser narrada" (AV, 219)
} 
tínuo em relação tanto ao caráter desse bem como também em relação ao autoconhecimento do próprio agente moral. Quer dizer, é no próprio processo da busca, de enfrentamento dos perigos, das ameaças, tentações e distrações particulares envolvidas nessa trajetória, com seus episódios e incidentes peculiares, que o objetivo da busca vai ser entendido.

As virtudes vão ser exatamente aquelas disposições que darão sustentáculo às práticas e que nos possibilitarão o acesso a seus bens internos, ao mesmo tempo que também "nos manterão no tipo relevante de busca pelo bem, habilitando-nos a superar os perigos, ameaças, tentações e distrações que encontraremos, e que nos fornecerão um crescente autoconhecimento e um crescente conhecimento do bem" (AV, 219). Com isso Maclntyre pode, então, nos oferecer uma definição, ainda que provisória, do que significa a boa vida para o homem, isto é, do telos que orienta a ação do homem numa vida humana considerada como um todo: "a boa vida para o homem é a vida gasta procurando a boa vida para o homem, e as virtudes necessárias para esse procurar são aquelas que nos capacitarão a entender o que mais e mais é a boa vida para o homem" (AV, 219).

Mas essa definição da boa vida para o homem e do papel das virtudes na busca dessa boa vida ainda exige um último passo na direção do terceiro estágio do conceito de virtude, uma vez que tais definições ainda parecem esvaziadas, um pouco sem alma. Para Maclntyre, é preciso providenciar o último recheio, o conteúdo final desse complexo conceito de virtude capaz de dar unidade à tradição aristotélica de pesquisa racional. $\mathrm{E}$ isso tem a ver com o fato de que tanto a busca pelo bem, como o exercício das virtudes, não podem ser procurados por cada um de nós somente enquanto indivíduos, como se estivéssemos isolados das comunidades históricas a que pertencemos e da qual derivamos nossa identidade. Maclntyre concebe a filosofia moral, portanto, a reflexão moral, como um enclave entre a filosofia, a sociologia e a história, quer dizer, não se pode pensar o agente moral e sua identidade fora dos âmbitos sociais e da história narrada da qual ele faz parte. Nesse sentido, a conceituação da virtude também não pode estar fora dessa tríplice determinação, seu papel e função também têm de ser definidos em torno desses mesmos elementos. Viver a boa vida varia concretamente em função das circunstâncias - mesmo quando é a mesma concepção da boa vida e o mesmo conjunto de virtudes que estão encarnados numa vida humana - não apenas porque somos indivíduos diferentes vivendo circunstâncias diferentes, mas porque carregamos uma identidade social particular. Isso significa dizer que minha identidade, meu eu não pode ser separado dos papéis e do status social e histórico que vivencio, pois a história da minha vida está inserida na história daquelas comunidades das quais retiro minha identidade.

Entretanto, Maclntyre adverte que o fato do eu encontrar sua identidade moral mediante seu pertencer a comunidades como a família, a vizinhança, a cidade e a tribo, não significa que o eu esteja preso às 
limitações da particularidade dessas formas de comunidade, não significa que não possua qualquer capacidade crítica e esteja condenado às determinações da particularidade social em que está mergulhado. Essas particularidades morais constituem o dado inicial, o ponto de onde começar a mover-se, a lançar-se para além de tais particularidades na busca do bem, do universal; mas uma busca na qual a particularidade nunca vai poder ser deixada para trás ou obliterada. Quer dizer, minha identidade, aquilo que sou é em grande parte oriundo do que herdei, de um passado específico que está presente de alguma forma no meu presente, porque sou parte de uma história, uma história que, reconhecendo ou não, gostando ou não, é um dos sustentáculos de uma tradição. E tradição entendida aqui não somente como um modo de compreender uma prática particular transmitida e remodelada mediante muitas gerações, mas sim como uma discussão historicamente estendida e encarnada socialmente, em parte acerca dos bens que constituem a tradição, dos bens cuja busca Ihes dá sentido e propósito.

Maclntyre se refere às tradições sociais mais amplas que se construíram historicamente como formas de vida portadoras de um vívido debate interno em torno do que seja a boa vida e o bem para o homem. Uma tradição, nesse sentido, é uma história de conflitos, é uma narrativa dos debates que conduziram a sua formulação ao estágio atual. Uma tradição é o terreno onde todo e qualquer raciocínio tem lugar, transcendendo por meio da crítica e da invenção as limitações do que foi até aqui pensado nessa tradição, isso valendo tanto para a física como para a lógica medieval, numa busca dos bens que se estende muitas vezes por muitas gerações. Da mesma forma que a busca de cada indivíduo pelo seu bem está, de um modo geral, inserida no contexto definido pelas tradições das quais sua vida faz parte, assim também ocorre com os bens internos às práticas e os bens de uma vida particular. A história de uma prática contemporânea nossa, de um modo geral, está caracteristicamente inserida nos termos da história mais ampla e mais longa da tradição que nos legou essa prática em sua forma atual, assim como "a história de cada uma de nossas vidas, em geral e caracteristicamente, está imersa e é tornada inteligível nos termos das histórias mais amplas e mais antigas de um sem número de tradições" (AV, 222).

Como as tradições têm um caráter histórico, quer dizer, nunca são estáticas nas suas formulações, sofrem um processo permanente de recriação e transformação, não significa necessariamente que vão existir e permanecer ad eternum, elas também podem decair, desintegrar e desaparecer. 0 que vai sustentar e reforçar ou enfraquecer e destruir uma tradição é precisamente o exercício ou a falta do exercício das virtudes relevantes. 0 sentido e propósito das virtudes consiste não somente em manter as relações necessárias para que a variedade de bens internos das práticas possa ser obtida, e nem somente em garantir a forma de uma vida individual na qual esse indivíduo pode perseguir seu bem como o bem de sua vida inteira, "mas também em sustentar 
aquelas tradições que providenciam para as práticas e para as vidas individuais o contexto histórico necessário a elas" (AV, 223).

Nesse sentido, uma virtude em particular vai ser essencial mesmo para a sobrevivência de qualquer tradição, prática ou instituição: a virtude do senso das tradições às quais alguém pertence ou às quais se confronta. Segundo MacIntyre, possuir essa virtude não é ser um conservador, não é querer manter as coisas tal como estão aí, mas sim ter uma percepção precisa daquelas possibilidades futuras que 0 passado tornou possível para o presente, visto que "tradições vivas, justamente porque continuam uma narrativa ainda não completada, confrontam um futuro cujo caráter, determinado e determinável, na medida em que possui algum, deriva do passado" (AV, 223). No âmbito do raciocínio prático, a posse dessa virtude não é caracterizada apenas pelo conhecimento de um conjunto de generalizações ou máximas que dão às nossas inferências práticas suas premissas maiores, mas pelo tipo de capacidade para julgar que 0 agente possui em saber como selecionar entre 0 estoque de máximas e como aplicá-las em situações particulares. Quer dizer, aqueles que possuem o senso das tradições possuem as virtudes que os habilitam a perseguir o seu próprio bem e o da tradição deles, mesmo em situações definidas pela necessidade da escolha dilemática, trágica.

$\mathrm{Na}$ medida em que toda filosofia moral tem uma sociologia como sua contrapartida, o modo de compreender a vida social que está presente na tradição das virtudes é um tipo muito diferente daquele que é dominante na cultura contemporânea do individualismo burocrático; daí porque nessa cultura "concepções de virtude tornam-se marginais e a tradição das virtudes permanece central somente nas vidas dos grupos sociais cuja existência está nas margens da cultura central" (AV, 225). Não é à toa, portanto, que o conceito de virtude seja transformado nessa cultura, ou que nela surjam novas concepções de virtude, e que a história de sua transformação na modernidade seja a história de um tipo de degeneração. A tradição das virtudes, assim, sobrevive, de um modo mais ou menos coerente e não deformado, apenas naquelas comunidades cujos vínculos históricos com o seu passado ainda permanece forte.

Para Maclntyre, apesar dos esforços de três séculos de filosofia moral e um de sociologia, a perspectiva do individualismo liberal da modernidade, que representou a degradação do conceito de virtude, ainda não conseguiu estabelecer uma posição coerente e racionalmente defensável; e só o restabelecimento da tradição aristotélica é que trará de volta a inteligibilidade e a racionalidade de nossas atitudes e compromissos morais. Mas ele admite que, a despeito de considerar sua argumentação como racionalmente convincente, seria imprudente não reconhecer diversos tipos de objeção oriundos de pontos de vista diferentes contrários a essas suas conclusões. 0 problema é que em filosofia dificilmente argumentos tomam a forma de uma prova, a maioria dos argumentos bem sucedidos em torno de questões centrais da filosofia 
nunca assume essa forma, conseqüentemente aqueles que desejam resistir a alguma conclusão particular raramente estão sem qualquer recurso. 0 que não significa dizer que questões centrais na filosofia não possam ser solucionadas, e sim que "quando uma questão é resolvida, é freqüentemente porque as partes contendoras - ou alguma delas - afastaram-se da disputa e se perguntaram, de um modo sistemático, quais são os procedimentos racionais apropriados para resolver este tipo particular de disputa" (AV, 260).

Maclntyre, diante dos desafios colocados pela desordem da linguagem moral e da moralidade em nossa época, do desacordo crônico instalado no debate moral contemporâneo, defende que chegou a hora em que é imperativo realizar essa tarefa para a filosofia moral, em que é preciso construir uma explicação sistemática da racionalidade pressuposta pela tradição das virtudes, de tal forma que o debate moral e a linguagem da moralidade percam essa aparência de descalabro que se apresenta na cultura contemporânea. Segundo ele, estamos numa época em que se faz historicamente necessário a construção de novas formas de comunidade onde a vida moral possa ser sustentada de tal forma que a moralidade e a civilidade possam sobreviver às épocas vindouras do barbarismo e da escuridão.

\section{A posologia: a tradição de pesquisa racional como paradigma}

0 problema que emerge do diagnóstico e do remédio proposto por Macintyre para a desordem moral de nosso tempo é que, ao recusar defender um padrão de racionalidade a-histórico e enfatizar a incomensurabilidade e a descontinuidade das teorias éticas, não estaria caindo no relativismo que, no fundo, afirma a validade de toda e qualquer teoria ética e, dessa forma, postulando uma conceituação de racionalidade que desemboca num empirismo empobrecido ou mesmo num irracionalismo desmedido? Podemos sair dessa perigosa encruziIhada e enfrentar os problemas gerados pela incomensurabilidade das teorias éticas, sem que passemos a afirmar uma certa arbitrariedade das fundações do agir moral? A que bases racionais, então, pode apelar a crítica filosófica da moralidade contemporânea para fugir dessa profunda desmedida que se abre no seu horizonte em função do emotivismo?

Para responder a essas questões, Maclntyre buscou inspiração nas similaridades com o caso das ciências naturais, no terreno teórico aberto pela filosofia da ciência kuhniana, essencialmente consciente da dimensão histórica da racionalidade científica, e que já enfrentara também aquela mesma acusação de irracionalismo ${ }^{7}$. Esse recurso à reflexão

$7 \mathrm{PH}, 40$. 
kuhniana por MacIntyre adquire todo seu sentido pela similaridade das situações enfrentadas pela filosofia da ciência pós-kuhniana e pelo pensamento historicista, pano de fundo da reflexão macintyreana. A partir do trabalho de Kuhn, a filosofia da ciência abandonou crescentemente a conexão positivista entre verdade, racionalidade e progresso, passando a operar com a perspectiva de visões de mundo diferentes e incomensuráveis, que não podem ser comparadas entre si usando $\underline{o}$ critério de verdade, uma vez que isso pressupõe possuirmos uma concepção absoluta acerca das maneiras de ser do mundo8.

A estratégia de MacIntyre e dos kuhnianos para oferecer uma saída diferente do ceticismo nietzscheano, e que não caia na acusação de relativismo ou de irracionalismo, é tentar mostrar que a mudança conceptual pode ser ainda racional, mesmo sem qualquer pretensão de estar lançando mão de uma perspectiva que supostamente tenha maior grau de validade absoluta. Ou seja, podemos usar uma noção "interna" de racionalidade, segundo a qual é racional mudar de uma visão ou teoria ética para outra, não porque uma possua "a" verdade ou uma validade absoluta, mas porque ela é capaz de resolver problemas, incoerências, anomalias, inconsistências e limitações das teorias e esquemas morais anteriores, e dessa forma constituir um avanço sobre eles em termos relativos, e não absolutos, dentro da história dessa mesma tradição.

A proposta de MacIntyre é articular e justificar uma teoria ética vinculada à tradição, por meio de uma concepção da racionalidade prática também vinculada à tradição, mas que, ao mesmo tempo, essa racionalidade não seja relativa, isto é, que não é a priori incomensurável com concepções de racionalidade alternativas de outras tradições. Noutras palavras, uma racionalidade que encontra seu sentido e funcionalidade no interior de uma tradição particular, mas que também é capaz de enfrentar e se abrir às posições de suas rivais, não se fechando engessadamente nos seus próprios termos, nem paralisando o debate que seu encontro com essas alternativas rivais gera como necessário para a afirmação de seu próprio progresso e crescimento - encontro esse que pode mesmo resultar em sua própria destruição. Uma racionalidade que, a despeito de ser visceralmente vinculada a uma tradição, não se dissociando de nenhuma forma dela, possibilita que essa tradição, por sua vez, se aproprie de recursos teóricos que não são originalmente seus e que são inicialmente alheios ao seu esquema conceptual, para com isso enfrentar mais qualificadamente os problemas que atravessam sua trajetória histórica.

Em MacIntyre temos uma concepção de pesquisa racional na qual a justificação racional é um empreendimento essencialmente histórico, visto que é forjada no interior de uma tradição social e intelectual

8 STERN (1994) 150. Ver KUHN (1992). 
particular como uma narrativa que dá conta de como os princípios primeiros das teorias, que são constituídos pela tradição e constitutivos dela, foram estruturados e construídos, de como eles chegaram a ser 0 que são hoje. Numa tradição de pesquisa e de justificação racionais, as teorias são construídas de tal maneira que certas teses tem 0 estatuto de primeiros princípios, a partir dos quais todos os outros elementos teóricos vão ser justificados por derivação deles. Tais primeiros princípios e, por conseguinte, toda a estrutura da teoria da qual fazem parte, são justificados não por meio de sua aceitação universal e absoluta por toda e qualquer pessoa presumivelmente racional com base em critérios neutros, mas sim por meio da superioridade racional da estrutura atual em relação a todas as outras tentativas anteriores de formular tais princípios e teorias no interior dessa tradição particular, como também em relação ao confronto com os inimigos externos à tradição que rejeitam seus acordos internos fundamentais, sempre empregando os conceitos e padrões pelos quais se define. Nesse sentido, a justificação racional vai ser uma narrativa histórica da pesquisa e do debate no interior da tradição e também uma narrativa do debate e da discordância com as tradições adversárias, debates esses que permitem a identificação adequada dos compromissos da tradição em particular, da sustentação adequada ou não dos primeiros princípios que são constitutivos e constituintes de sua racionalidade.

Os problemas implicados na avaliação de uma tradição de pesquisa, segundo Maclntyre, têm dois níveis: um primeiro, no qual se tem a tarefa de avaliar racionalmente afirmações opostas e conflitantes numa mesma tradição; e, um segundo, em que a tarefa é avaliar asserções rivais quando cada uma delas desenvolveu-se dentro de tradições muito diversas e conflitantes. No primeiro caso, pode-se recorrer a uma série de padrões relativamente não problemáticos para fazermos a comparação, procurando determinar até que ponto o pensador posterior soluciona os problemas apresentados pelo pensador anterior ou aqueles que ele considerou insolúveis, bem como determinar a extensão com que o posterior oferece recursos conceituais ou teóricos sem as limitações dos recursos de seu predecessor ${ }^{9}$. No segundo caso, temos concepções de moralidade e de racionalidade prática que são propostas em esquemas conceituais muito diferentes, que empregam modos de caracterização e argumentação, por vezes totalmente diferentes e incompatíveis, como, por exemplo, os de Hume e Aristóteles. Como, então, decidir entre posições rivais e mutuamente exclusivas, se não há um padrão neutro independente de qualquer tradição e racionalmente justificável, ao qual possamos recorrer? Aqui, pretende Maclntyre, o reconhecimento da diversidade de tradições de pesquisa, cada uma com seu modo específico de justificação racional, não implica necessariamente que as divergências entre tradições rivais e incompatíveis não

9 J R, 354.

Síntese, Belo Horizonte, v. 28, n. 90, 2001 
possam ser racionalmente resolvidas, pois "do ponto de vista das tradições de pesquisa racional, o problema da diversidade não é abolido, mas transformado, de maneira a viabilizar sua solução" (JR, 20).

Para isso, a nosso ver, ele buscou na reflexão kuhniana os recursos conceituais para modelar sua concepção da racionalidade das tradições, entendendo-as como paradigmas do pensar e do agir morais, para mostrar que a mudança conceptual pode ser racionalmente estabelecida, sem contudo apelarmos para padrões de racionalidade a-históricos; e, com isso, preservar a historicidade, que é tão cara ao ser humano e às suas ações, especialmente no âmbito da moralidade. Para Maclntyre, as relações que uma filosofia da ciência adequada tem com a história da ciência, como brilhantemente Kuhn fez valer em sua reflexão sobre 0 problema da explicação da racionalidade científica, são similares às relações que a filosofia moral tem com a história da moralidade e sua importância para o esclarecimento da racionalidade ética ${ }^{10}$.

A argüição kuhniana acerca da natureza da racionalidade da ciência e dos problemas gerados pela incomensurabilidade das teorias rivais, argüição esta endossada por Maclntyre e trazida para o âmbito da filosofia moral, pode ser resumida na tese de que um corpo de teoria científica incomensurável, ou paradigma, pode falar para outros através do tempo, não somente providenciando um conjunto melhor de soluções a seus problemas centrais, mas também providenciando uma explicação histórica do porquê algumas das experiências-chave dos seus defensores, lutando para superar os problemas próprios deles, foram o que foram. É esse teste de superioridade racional, uma espécie de explicação histórica, que nos permite avaliar as teorias rivais entre si, sem contudo recorrer a padrões atemporais absolutos e "externos" às teorias em questão ${ }^{11}$. Isso significa que a racionalidade e a natureza progressiva da filosofia moral não reside no seu movimento gradual na direção de objetivos de validade atemporal, mas no fato de que cada tradição pode ser vista como transcendendo as limitações de suas formulações predecessoras, avançando soluções em relação àquele

10 "A história da moralidade-e-da-filosofia-moral é a história de sucessivos desafios a alguma ordem moral preexistente (...). É somente por referência a esta história que questões de superioridade racional podem ser estabelecidas. A história da moralidade-e-da-filosofia-moral escrita deste ponto de vista é tão integrada ao empreendimento da filosofia moral contemporânea quanto a história da ciência o é para o empreendimento da filosofia da ciência contemporânea" (AV, 269).

11 “É na capacidade de uma filosofia-moral-particular-articulando-as-pretensõesde-uma-moralidade-particular identificar e transcender as limitações de sua rival ou rivais, limitações que podem ser - embora elas não possam de fato ter sido - identificadas pelos padrões racionais ao qual os protagonistas da moralidade rival estão comprometidos por sua fidelidade a ele, que a superioridade racional daquela filosofia moral particular e daquela moralidade particular emerge" (AV, 269). 
conjunto de dificuldades que as tradições ou formulações anteriores de uma mesma tradição não conseguiram dar conta, uma perspectiva que vale tanto para as ciências como para a filosofia moral ${ }^{12}$.

\begin{abstract}
"Será assim, algumas vezes pelo menos, possível para defensores de cada tradição entender e avaliar - pelos seus próprios padrões - as caracterizações de suas posições apresentadas pelas rivais. E nada os impede descobrir que essas caracterizações Ihes revelam traços de suas próprias posições que até aquele momento não foram notados ou considerações que, pelos seus próprios padrões, teriam de ter tido em mente, mas não tinham. Na verdade, nada evita a descoberta de que a tradição rival oferece explicações convincentes da fraqueza, da inabilidade em formular ou resolver problemas adequadamente, de uma variedade de incoerências na própria tradição de alguém para as quais os recursos dessa mesma tradição não foram capazes de oferecer uma interpretação convincente" (AV, 276-7).
\end{abstract}

Esse recurso a uma racionalidade "interna", baseada na abordagem histórica das diferentes teorias rivais, mesmo no campo das teorias científicas, resulta da impossibilidade de obtermos um critério ou padrão de argumentação neutro, por não podermos apelar a dados independentes e neutros aportados pela observação, como também porque quais dados nós vamos considerar relevantes dependerá de qual dos paradigmas rivais adotarmos primeiro. Com isso, podemos alterar nossa concepção tradicional do progresso científico e moral, sem contudo cair no relativismo, na medida em que a inteligibilidade do mundo vai ser sempre construída a partir dos parâmetros internos a cada paradigma, e sua superioridade racional em relação aos rivais vai ser construída em seus embates históricos com os problemas que se propõe resolver e no enfrentamento das objeções que lhes são postas nos períodos de crise, fazendo com que uma narrativa histórica adquira uma posição fundamental na conceituação do que será considerado progresso ou degradação teórica.

Paradigmas científicos ou tradições morais podem ocasionalmente se romper, isto é, pelos seus próprios padrões de crescimento e ruptura, e um encontro com tradições rivais pode, deste modo, providenciar boas razões, seja para tentar reconstruir a própria teoria de maneira radical, seja para abandoná-la, não havendo qualquer princípio determinante necessário regulando todo esse evolver histórico.

"O que emerge, então, talvez surpreendentemente, éque a história da ciência natural é de uma certa maneira soberana sobre as ciências naturais. Pelo

\footnotetext{
12 Para Maclntyre, pode mesmo existir casos em que uma determinada tradição de pesquisa, definida por um corpo de teoria, degenere no tocante à coerência ou esterilidade, ou não consiga acomodar novas descobertas sem sucumbir em incoerências, e seus seguidores terem bons fundamentos para rejeitá-la, sem contudo claramente terem alguma boa razão para selecionar algum outro corpo de teoria particular alternativo como merecedor de sua adesão.
} 
menos em questões relativas àqueles corpos de teoria de grande escala incomensuráveis que Kuhn primeiro identificou, a teoria superior na ciência natural é aquela que aporta fundamentos para um certo tipo de explicação histórica, que dá a uma narrativa histórica uma inteligibilidade que de outra forma não teria. (...) As ciências da natureza, a despeito do tipo de mente antihistórica que freqüentemente informa as maneiras nas quais elas são ensinadas e transmitidas, não podem escapar de seu passado" (PH, 44).

Da mesma maneira esse veredicto é estendido por Maclntyre à filosofia moral. Nos conflitos e debates entre tradições rivais, no qual o desacordo é sistemático, de tal maneira que aparentemente elimina a possibilidade de qualquer padrão comum para a resolução racional do desacordo, cada uma das tradições rivais terá sua própria problemática interna, seus momentos de incoerência, seus problemas não resolvidos, julgados segundo seus próprios padrões do que é problemático, do que é coerente, e do que é uma solução satisfatória, padrões esses explicitados na narrativa histórica que Ihe é constitutiva.

0 que constitui a superioridade racional do ponto de vista filosófico de uma tradição sobre outra é, então, sua habilidade

"em transcender as limitações daquele outro, providenciando de seu próprio ponto de vista uma explicação e entendimento melhores dos fracassos, frustrações e incoerências do outro ponto de vista (fracassos, frustrações e incoerências, isto é, como julgadas pelos padrões internos àquele outro ponto de vista) do que aquele outro ponto de vista pode dar de si mesmo, de tal forma que nos capacita a dar uma melhor interpretação histórica, uma narrativa verdadeira mais adequada e inteligível daquele outro ponto de vista e seus sucessos e fracassos, do que ele pode providenciar para si mesmo" (PH, 47).

Resulta que, assim como as conquistas das ciências naturais vão, ao final de tudo, ser julgadas nos termos das conquistas da história daquelas ciências, também as conquistas da filosofia moral vão ser avaliadas, no final das contas, nos termos das realizações da história da filosofia moral. Dessa forma, julgando as teorias morais em termos históricos, Maclntyre crê superar o desafio do ceticismo nietzscheano, ao mesmo tempo abandonando as posições assumidas pelo absolutismo dogmático. 0 que nos capacita a fazer uma avaliação e uma escolha racional e objetiva entre teorias competidoras, morais ou científicas, não é aplicar padrões absolutos, mas somente padrões históricos. É introduzindo uma perspectiva histórica que teremos bases racionais para mudar de uma teoria para outra, sem contudo ter de mostrá-la como válida em termos absolutos, pois é somente localizando as teorias na história, "quando visamos as demandas por justificação em contextos muito particulares de tipo histórico, que estamos livres do dogmatismo ou da capitulação ao ceticismo" (EC, 471).

Se abstrairmos quaisquer teses particulares do contexto das tradições de pesquisa racional nas quais foram formuladas originalmente e as 
lançarmos num debate que não leva em conta as particularidades de caráter, história e circunstâncias dos indivíduos e das tradições, estaremos destruindo a possibilidade de um diálogo racional por meio do qual poderíamos mesmo avaliar argumentativamente a aceitação ou rejeição racional de uma tradição de pesquisa particular. Quer dizer, fora das tradições e das circunstâncias históricas que elas encarnam não há possibilidade de racionalidade, senão estaríamos operando no vazio, usando incoerentemente os fragmentos e partes de diferentes e incompatíveis tradições ao mesmo tempo. Isso significa que, do ponto de vista da racionalidade das tradições, a pretensão liberal de um debate racional cujas regras e critérios seriam válidos para qualquer pessoa racional não faz o menor sentido e desembocaria na própria condição contraditória da prática e do discurso da moralidade contemporânea. Pois toda tradição de pesquisa racional em boa ordem vai ser capaz de narrar uma história diferente desse mesmo debate, bem como oferecer uma caracterização diferente das posições adversárias.

Nesse sentido é que Maclntyre afirma que este deveria ser o ponto inicial de uma discussão em torno de questões substanciais favoráveis ou contra as tradições de pesquisa racional e favoráveis ou contra a anti-tradição: o reconhecimento inicial de que "devemos começar a falar como protagonistas de uma parte envolvida, ou então permanecer em silêncio" (JR, 430). Ou seja, o que nós temos substancialmente disponível é apenas 0 onde e o como começar nossa discussão em torno das questões éticas e da racionalidade prática. Mas, como já nos ensinou Descartes, saber como começar é uma das tarefas mais difíceis na Filosofia, e o fato de já termos esse começo é uma conquista fundamental para poder efetivar um diálogo racional entre as tradições. Só na medida em que nos filiamos a alguma tradição particular de pesquisa, isto é, tomandose por base nossa relação com um passado social e intelectual específico, buscando dar continuidade à história de sua pesquisa até o presente, é que podemos, então, viabilizar o debate racional. Com isso, 0 conjunto de questões que possam nos guiar nesse empreendimento será:

"a que questões, no debate contemporâneo, nos remete essa história particular? Que recursos nossa tradição particular nos oferece nessa situação? Podemos, por meio desses recursos, compreender as real izações e os sucessos, os fracassos e a esterilidade de tradições rivais mais adequadamente do que seus próprios adeptos? Mais adequadamente, segundo nossos padrões? M ais adequadamente, segundo os padrões deles?" (JR, 430).

Para Maclntyre, são as histórias ofertadas por cada tradição que terão de dar respostas a essas questões, que nos permitirão responder às questões morais que nos afligem, tal como aquela que está no título de um de seus livros: justiça de quem? qual racionalidade? Como não há nenhum padrão argumentativo universal que possa mostrar tais respostas, é o modo como cada tradição vai escrever suas histórias que vai 
nos mostrar qual delas pode ser mais bem sucedida, porque "reivindicações rivais da verdade de tradições de pesquisa conflitantes dependem, para serem justificadas, da adequação e do poder explicativo das histórias que os recursos de cada uma delas permitem a seus adeptos escrever" (JR, 431). Quer dizer, um primeiro passo necessário para duas tradições rivais e incomensuráveis conseguirem travar um diálogo racional é que cada uma delas construa, para elas próprias, a história da outras, mas escrita do ponto de vista da outra e empregando os modelos de sucesso ou fracasso racional internos à outra. E dois traços desse diálogo racional são cruciais: o primeiro, é a admissão, por parte de cada tradição, do falibilismo, sem o qual todo e qualquer diálogo se torna impossível, pois

"só podemos aprender quais recursos intelectuais e morais nosso próprio ponto de vista, nossa própria tradição de pesquisa prática e teórica possuem, bem como quais recursos morais e intelectuais suas rivais podem possuir, quando tivermos entendido nosso próprio ponto de vista de um modo que assuma com inteira seriedade a possibilidade de que, no fim, podemos, como seres racionais, ter de abandonar esse ponto de vista" (IT, 121);

o segundo traço é, como já vimos, que não temos nenhum ponto de vista neutro, independente, fora do contexto de cada ponto de vista em competição, a partir do qual julgarmos que devemos abandonar uma tradição de pesquisa racional por deficiência na resolução de problemas. Daí que toda comparação vai ser sempre com base em algum ponto de vista particular, num processo que se estende, na verdade, para uma comparação das comparações, porque, segundo Maclntyre, "logo descobriremos que nossa tarefa não é tanto aquela de comparar Confucionismo e Aristotelismo, mas a de comparar as comparações confucionistas de Confucionismo e Aristotelismo com as comparações aristotélicas de Confucionismo e Aristotelismo" (IT, 121).

Como toda e qualquer comparação racional vai ser feita sempre a partir do ponto de vista de uma tradição particular de pesquisa, vai ser sempre inevitável que num encontro de tradições, na tentativa de um diálogo racional entre elas, "temos de começar discordando mesmo sobre como caracterizar aquilo sobre o que discordamos, se vamos fazer qualquer movimento, mesmo que seja um movimento com atropelos, meio lento e hesitante, na direção do acordo racional" (IT, 122). Noutras palavras, o que esses elementos nos revelam é, na verdade, o caráter paradigmático das tradições de pesquisa racional, que em Maclntyre tais tradições podem ser entendidas como paradigmas, no sentido kuhniano, da racionalidade ética ou prática. Da mesma forma que não é possível falar de uma racionalidade no âmbito da pesquisa científica fora dos paradigmas, assim também não há racionalidade fora das tradições, muito menos critérios de superioridade ou de progresso racional que não sejam os padrões internos de racionalidade de cada tradição, a partir dos quais podemos fazer comparações. 


\section{Conclusão}

Para Maclntyre, os problemas na teoria e prática morais de nosso tempo são resultantes da dissolução crescente e da agudíssima crise epistemológica do paradigma universalista das sociedades herdeiras da cultura iluminista. É o fracasso desse paradigma universalista, depois de três séculos e meio de tentativas malsucedidas, que está nas raízes de nossas dificuldades. Dificuldades essas que começaram quando a modernidade abandonou o paradigma teleológico aristotélico da moralidade e lançou toda a linguagem e a prática morais na busca de padrões universais neutros, a-históricos, cuja validade se colocava acima das tradições morais e sociais, desembocando no buraco negro do emotivismo contemporâneo que dissolve toda a racionalidade prática em nome das vontades individuais, de um subjetivismo autofágico e incoerente. Segundo ele, faz-se necessário que abandonemos, se não de todo, pelo menos a maior parte, do ethos liberal moderno, modelado pelo paradigma ético iluminista, cujo fracasso em fornecer uma orientação clara e precisa para o agir humano - por vezes, deixada para a mão invisível do mercado - foi o resultado maior do abandono do paradigma ético clássico, a tradição aristotélica das virtudes. Nesse sentido, a crise moral contemporânea só pode ser solucionada se retomarmos esse paradigma anterior à modernidade - e que sobreviveu nas margens das modernas sociedades liberais -, mas reformulado segundo as exigências epistemológicas e sociais contemporâneas, de tal maneira que a teoria e a prática morais recuperem sua qualidade racional.

O caos na moralidade contemporânea pode, então, ser visto como 0 resultado do abandono equivocado de um paradigma, a tradição aristotélica das virtudes, em prol de um novo paradigma, a tradição universalista do Iluminismo, que desde seu início foi um projeto fracassado, um paradigma destinado a entrar em crise epistemológica permanente, que até hoje esconde seus problemas e dificuldades com uma série de máscaras morais e pseudo-conceitos que disfarçam sua essência emotivista, sua dimensão irracional. Somente um paradigma de racionalidade ética que encarne a contingência e a natureza histórica da teoria e da prática morais, bem como sua indissociabilidade com uma ordem social, portanto, que se estruture e se reconheça como uma tradição moral de pesquisa racional, é que vai ser capaz de desvelar a especificidade de nossas dificuldades no cenário moral e oferecer algum tipo de solução substancial para os problemas de irracionalismo que enfrentamos na vida moral de nossas sociedades. Para Maclntyre, somente o retomar da ética aristotélica das virtudes, como uma tradição moral de pesquisa racional, é que assume tal perspectiva e vai nos aportar os recursos conceituais para enfrentar o desafio que Nietzsche colocou para toda e qualquer filosofia moral em nossa época: a de não 
se mostrar como máscara de uma vontade de potência. Somente 0 restabelecimento do paradigma da tradição das virtudes é que vai permitir que 0 agir e 0 pensar morais readquiram a qualidade racional, fundada numa visão do telos humano construída como uma narrativa histórica que situa as ações morais no quadro de um conjunto de princípios e padrões racionais resultantes de debates internos e externos, formulados no enfrentamento das crises epistemológicas e das questões emergidas no interior das práticas constitutivas da tradição de pesquisa e ação moral.

Nesse sentido, a referência à epistemologia kuhniana é uma das fontes fundamentais da filosofia moral de Maclntyre, mais especialmente de sua estruturação da racionalidade das tradições de pesquisa moral. Podemos ver que Maclntyre propõe a retomada da ética aristotélica das virtudes com uma instrumentação conceptual contemporânea, e não um simples retorno a um enquadramento pré-moderno, como se nossas produções materiais e intelectuais não fossem históricas e como se estivéssemos apenas nos equivocado na efetivação de alguma essência anteriormente estabelecida e determinada como nosso horizonte. Ele é filosoficamente um pensador contemporâneo, a despeito de valorizar um instrumental teórico que tem raízes na Grécia antiga e que julga ainda poder contribuir para a solução de nossos problemas. Sua reflexão oferece uma alternativa razoável, embora muito polêmica, para a compreensão da crise moral que assola a arena contemporânea, colocando-nos de fora da versão iluminista standard - e seus subprodutos - que tem predominado na prática e na teoria moral, de tal forma que possamos vê-la por uma outra ótica e nos perguntemos pelos seus limites e problemas, se ela não nos levou a abandonar alguma coisa que era essencial para a sustentabilidade da racionalidade ética. Maclntyre não se comporta como o garoto rebelde que depreda as vidraças à vista com seu estilingue, lançando suas pedras contra os males da modernidade iluminista e suas conseqüências para a teoria e a prática morais de nossa época.

Sua reflexão filosófica visa, antes de tudo, ofertar uma alternativa razoável para os que se encontram cobertos pelos telhados de vidro do paradigma iluminista, tentando fazer que o enfrentamento entre posições incomensuráveis, como a que existe entre a dele e a posição universalista liberal, não constitua um diálogo de surdos e nem um pacífico debate no interior das águas calmas e necessárias de padrões neutros e acima das particularidades das tradições. Seu objetivo é que tal confronto venha a se constituir como um movimento inicial no reconhecimento das diferenças, coisa que, segundo ele, talvez seja um dos processos mais difíceis no debate filosófico, mas, ao mesmo tempo, o ponto de partida fundamental para qualquer superação dessas diferenças. $E$, nesse propósito, a compreensão da natureza da racionalidade das tradições é um elemento primordial para possibilitar a afirmação 
das diferenças entre as tradições de pesquisa rivais e para compreender os processos de sua superação.

\section{Bibliografia}

BUBNER, R. Aristóteles y la filosofía práctica de nuestros días. IN: CASSIN, B. (org.). Nuetros gregos y sus modernos. Estrategias contemporáneas de apropriación de la antigüedad. [1992] Buenos Aires, Ediciones M anantial, 1994.

CARVALHO, H. B. A. de. Tradição e racionalidade na filosofia de Alasdair MacIntyre. São Paulo, Unimarco Editora, 1999.

BAYNES, K./ BOHMAN, J./ MCCARTHY, T. After Philosophy: End or Transformation? Cambridge, The M IT Press, 1987.

BERTI, E. La philosophie pratique d'Aristote et sa "réhabilitation" récente. Revue de Métaphysique et de M orale. № 2 (1990): 249-266.

Aristóteles no século XX. São Paulo, Loyola, 1998.

GUARIGLIA, O. El múltiple Aristóteles. Una visión de la filosofia práctica aristotélica desde la problemática contemporánea. Isegoría. № 1 (1990): 85-103.

KUHN, T. A estrutura das revoluções científicas. [1962] São Paulo, Perspectiva, ${ }^{3} 1992$.

MacINTYRE, A. Epistemological Crisis, dramatic narrative and the philosophy of science. The Monist, 60 (4): 453-72, 1977. (EC).

$\therefore$ HAUERW AS, S. (eds). Revisions. Notre Dame, University of Notre Dame Press, 1983.

After Virtue. [1981] London, Duckworth, 21985. (AV).

The Relationship of Philosophy to its Past. IN: RORTY, R.; SCHNEEW IND, J.B.; SKINNER, Q. (eds.) Philosophy in History. [1984] Cambridge, Cambridge University Press, ${ }^{6} 1993$, pp. 31- 48. (PH).

1990. (JR)

Justiça de quem? Qual racionalidade? [1988] São Paulo, Loyola,

Incomensurability, Truth, and the conversation between confucians and aristotelians about the virtues. IN: DEUTSCH, E. (ed.). Culture and Modernity. East-West philosophic perspectives. Honolulu, University of Hawaii, 1991, pp.104-122. (IT). 
Are Philosophical Problems Insoluble? The Relevance of System and History. IN: COOK, P. (ed.). Philosophical Imagination and Cultural Memory: Apropriating Historical Traditions. Durham, Duke University Press, 1993, pp.65-82. (SH).

STERN, R. Maclntyre and Historicism. IN: HORTON, J.; MENDUS, S. (eds). After MacIntyre. Notre Dame, University of Notre Dame Press, 1994. pp.146-60.

W ALLACH, John R. Contemporary Aristotelianism. Political Theory 20, 4 (1992): 613-641.

Endereço do Autor:

Condomínio Santa Mônica, Bloco 11, Apto. 302, Ininga

64049-902 Teresina - PI 